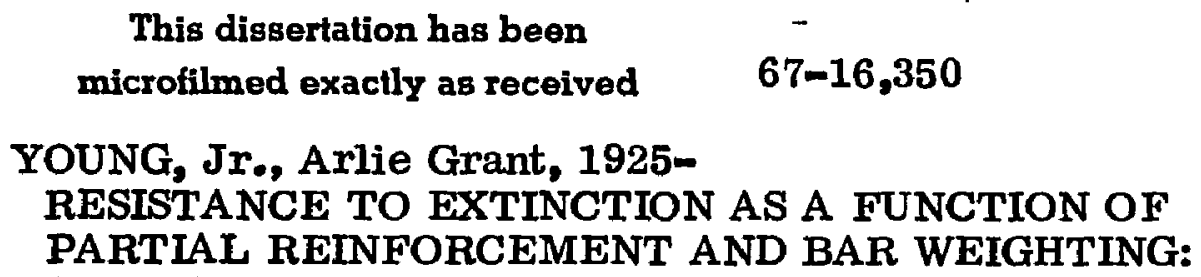

The Ohio State University, Ph.D., 1967

Psychology, experimental

University Microfilms, Inc., Ann Arbor, Michigan 


\section{RESISTANCE TO EXTINCTION AS A FUNCTION OF PARTIAL REINFORCEMENT AND BAR VEIGHTING:}

A WITHIN-S DESIGN

\section{DISSERTATION}

Presented in Partial Fulfillment of the Requirements for the Degree Doctor of Philosophy in the Graduate School of The Ohio State University

\section{By}

Arlie Grant Young, Jr., B.A., M.A.

** *t* *t* $*$

The Ohio State University 1967

Approved by

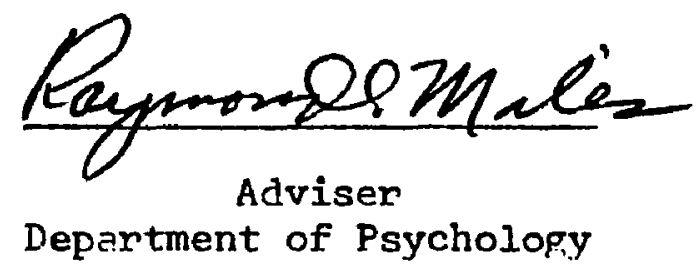




\section{ACKNOWLEDGMENTS}

The author expresses his sincere gratitude to his adviser, Dr. Raymond C. Miles, for his counsel during the planning and running of the experiment and critical reading of the manuscript. The author is also grateful to the other members of the committee, Dr. Delos D. Wickens, Dr. Donald R. Meyer, and Dr. Reed Lawson. 
VITA

\begin{abstract}
August 18, 1925 . . . Born - Eureka, Kansas
1964 . . . B.A., University of Utah, Salt Lake City, Utah

1964-1965 . . . Research Assistant, Department of Psychology, The Ohio State University, Columbus, Ohio

1965 . . . . M.A., The Ohio State University, Columbus, Ohio

1965-1966 . . . Teaching Assistant, Department of Psychology, The Ohio State University, Columbus, Ohio

1966-1967 . . . Pre-doctoral fellow, NSF training grant, The Ohio State University, Columbus, Ohio
\end{abstract}

\title{
PUBLICATIONS
}

Young, A. G. Resistance to extinction as a function of number of nonreinforced trials and effortfulness of response. J. exp. Psychol., 1966, 72, 610-613.

Uhl, C. N., and Young, A. G. Resistance to extinction as a function of incentive, percentage of reinforcement, and number of nonreinforced trials. J. exp. Psychol., (in press).

\section{FIELDS OF STUDY}

Major Field: Psychology

Studies in Learning. Professors Delos D. Wickens and Raymond C.Miles

Studies in Motivation. Professor Raymond C. Miles

Studies in Physiolopical Psychology. Professor Donald R. Meyer

Studies in Operant Conditioning. Professor Reed Lawson

Studies in Quantitative Methods. Professor James C. Naylor 


\section{CONTENTS}

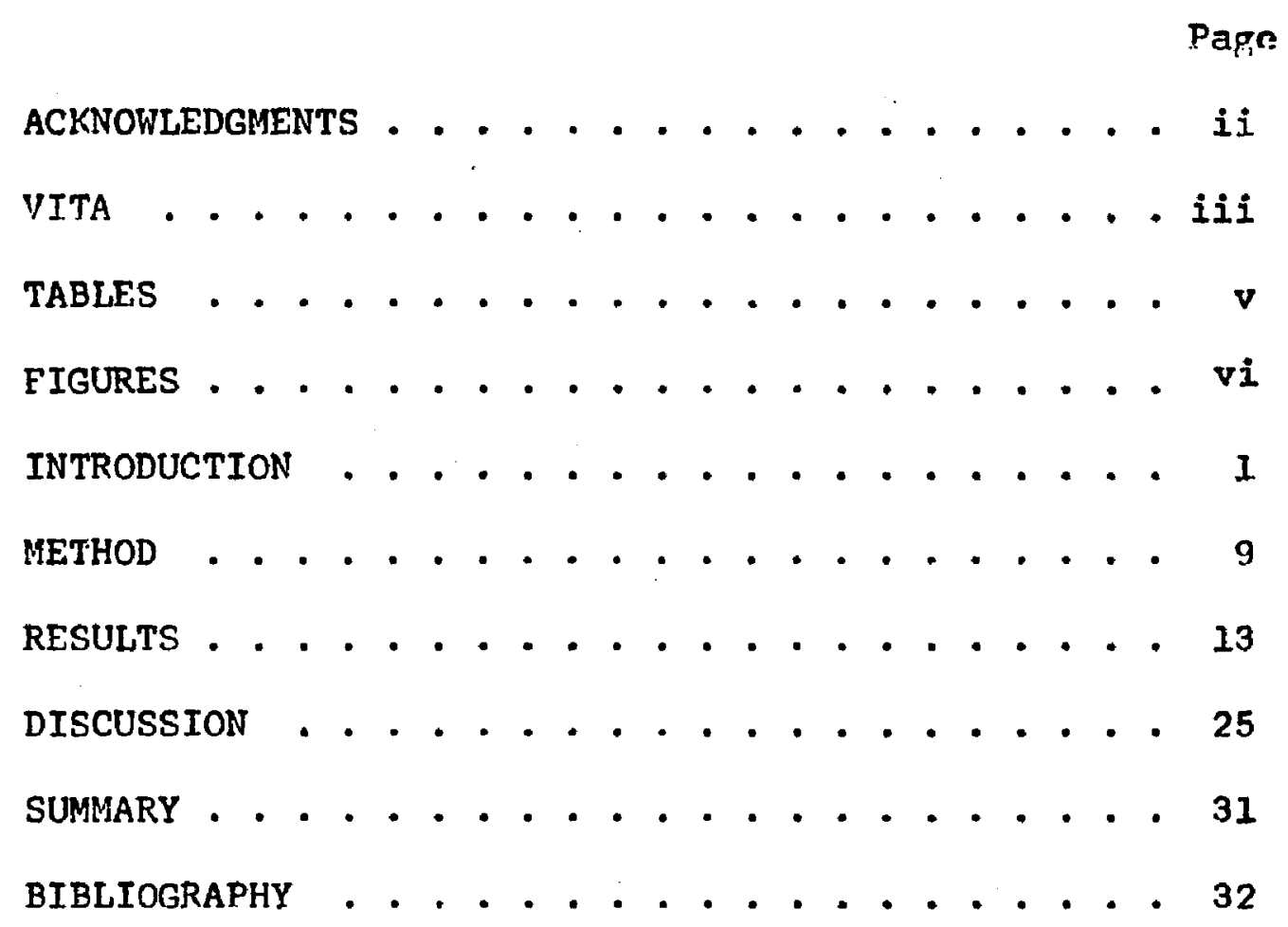




\section{TABLES}

Table

1. Analysis of Variance of Responses in Extinction

for Within-S Groups . . . . . . . . . . . 14

2. Analysis of Variance of Simple Interaction Effects for Hithin-S Groups . . . . . . . 15

3. Analysis of Variance of Simple Effects of Bar Weighting and Schedule at 2000 Total Trials 16

4. Analysis of Variance of Extinction Responses of Between-S (CRF-Trained) Groups . . . . . 23 


\section{FIGURES}

\section{Figure}

1. Mean Extinction Responses for Within-S Groups at 2000 Total Trials. . . . . . . . . 17

2. Mean Extinction Responses for Within-S Groups by Bar Weighting . . . . . . . . . . 19

3. Mean Extinction Responses for Within-S Groups by Schedule and Bar Weighting . . . . . 20

4. A Comparison of Mean Extinction Responses for Within-S and Between-S Groups by Schedule . 21

5. Mean Extinction Responses for Between-S (CRFTrained) Groups by Bar Weighting - . . . 24 


\section{INTRODUCTION}

The most critical problem with which a general theory of extinction must deal is the effect of intermittent reinforcement (PR), during acquisition, on resistance to extinction. It is well established that resistance to extinction is considerably augmented following training under conditions of PR, as compared to continuous reinforcement (CR.F) (cf. Jenkins \& Stanley, 1950: Lewis, 1960). This phenomenon, now termed the partial reinforcement effect (PRE), was reported by Skinner (1938); however, the significance of the phenomenon was not generally recognized until it was apain reported by Humphreys (1939). The PRE has since fenerated a considerable amount of research, and numerous theoretical formulations have been offered to account for it.

Humphreys' (1939) explanation of the PRE was based upon the expectancy of $\underline{S}$ that the unconditioned stimulus will follow the conditioned stimulus. Under CP.F training conditions there is a regular expectancy of reinforcement, whereas PR training produces an irregular expectancy of reinforcement. Extinction is more rapid following CRF training. because the shift from a regular expectancy of reinforcement to a regular expectancy of nonreinforcement is easier than is the shift from an inregular expectancy of reinforcement to a regular 
expectancy of nonreinforcement. Lewis (1960) suggests that expectancy theory has been rather generally discredited, and at present has few, if any, supporters.

An explanation of the PRE offered by Mowrer and Jones (1945) is the response-unit hypothesis. This formulation suggests that if the term response refers only to a behavior sequence leading to reinforcement, then PR training does not result in increased resistance to extinction. Certain facts about extinction argue against this formulation howevor (Capaldi, 1958), and in addition, this explanation seems to lack sufficient generality to include discrete trial training procedures, particularly if the trials are widely spaced. Skinner's (1938) explanation of the PRE was very similar to the response-unit hypothesis.

The discrimination hypothesis, which probably had its origins in expectancy theory, was first offered by Mowrer and Jones (1945), and has received strong empirical support (e.g., Bitterman, Fedderson, E Tyler, 1953: Elam, Tyler, E Bitterman, 1954). This hypothesis suggests that the more similar the stimuli in acquisition and extinction, the greater the resistance to extinction. Since the stimulus conditions in extinction are more similar to the stimulus conditions which obtain in PR training, it is therefore more difficult for the PR-trained S to discriminate between acquisition and extinction. Another early explanation of the PRE is the secondary reinforcement hypothesis (Denny, 1946) which suggests that the stimuli of the goal situation acquire secondary reinforcing properties on 
reinforced trials. Nonreinforced trials in acquisition and extinction therefore are secondarily reinforced, and any condition which tends to maximize the probability of seccndary reinforcers should increase resistance to extinction. Although the efficacy of secondary reinforcers to maintain responding has been empirically demonstrated, to offer this as a sole explanation of the PRE leads to logical difficulties and is not congruent with experimental evidence (e.g., Freides, 1957; Mason, 1957; Notterman, 1951).

Sheffield (1949) proposed what has been called an aftereffects theory to account for the PRE. This theory suggests that the stimuli following nonreinforcement are quite different from the stimuli which follow reinforcement. Under PR training conditions, if the aftereffects of nonreinforcement are present when a response is made and reinforced, then the response becomes conditioned to the stimuli associated with nonreinforcement. Although Sheffield offered empirical support for her hypothesis, attempts to replicate her experiment have been unsuccessful (Lewis, 1956; Wilson, Weiss, $\varepsilon$ Amsel, 1955), and other evidence has been offered which does not support the aftereffects theory (Katz, 1957: Tyler, 1956; Tyler, Wortz, \& Bitterman, 1953: Weinstock, 1954, 1958).

Weinstock $(1954,1958)$ has proposed that competing, responses account for the extinction of an instrumental response. Under PR training conditions, $\underline{S}$ makes competing responses in the goal box on nonreinforced trials; as PR training continues, however, these competing responses habituate. As habituation proceeds, the strength of the 
competing responses drops to some relatively low level; thus, these responses occur with a low frequency and there is little decrement in the strength of the instrumental response due to a nonreinforced trial. Under CRF training conditions competing responses never occur until extinction begins and they then account for a rapid loss of strength of the instrumental response.

Hulse and Stanley (1956) have suggested a similar explanation of the PRE. They suggest that on nonreinforced trials during acquisition the PR-trained $\underline{S}$ learns to make responses other than those of a consummatory nature. When extinction begins, the PRtrained $S$ makes these previously learned responses which quickly remove S from those stimuli which elicit consummatory responses. Thus, the consummatory response is extinguished more rapidly for the CRF-trained $\underline{S}$, resulting in more rapid extinction of the instrumental response.

Perhaps the theoretical formulation of the PRE which has generated more research than any other is that of Amsel (1958, 1962) (cf. Spence, 1960). Amsel suggests that the effect of nonreinforced trials is to elicit a frustrative reaction. Through the processes of stimulus generalization and higher order conditioning the frustrative reaction becomes anticipatory in fractional form, and the instrumental response becomes attached to the fractional anticipatory frustration-produced stimuli. This is the mechanism which produces the PRE in extinction. Since the frustrative reaction occurs on nonreinforced trials during, acquisition, 
this conditioning does not occur in the case of the CRF-trained $\underline{S}$. Kendler, Pliskoff, D'Amato, and Katz (1957) have presented essentially the same explanation with the exception that no emotional properties are ascribed to the fractional response.

Mowrer ( 1960 ) has proposed a theoretical formulation to account for the PRE which is an elaboration of the earlier discussed discrimination hypothesis. Mowner proposes that after the running response has been reinforced in the goal box on some few occasions, $\underline{S}$ will have an image (a conditioned sensation) of "goal-box-with-food:" during, the performance of future responses. On the first nonreinforced trial of PR training $\underline{S}$ is frustrated in the goal box fo: the first time. On the following (reinforced) trial, during the performance of the response, S "images" (remembers) the frustrating nonreinforced goal box experience of the previous trial, but this image is now followed by food in the goal box. Thus, the conditioned sensation (image) of the empty goal box is closely associated with reinforcement, and on future nonreinforced trials a generalization of the hope reaction (secondary reinforcement) from the image to the real thing occurs. When extinction begins, the after-response image of the PRtrained $\underline{S}$ is thus ambiguous, with the result that acquisition and extinction are hard to discriminate. In addition, since frustration has been previously associated with reinforcement, it is not effective as a source of counterconditioning of the strength of the instrumental response. The only after-response image of the CRFtrained $\mathrm{S}$ is that of reinforcement, and when extinction begins this 
image is suddenly controverted by the fact of nonreinforcement. Discrimination is precise, and the frustration produced by nonreinforcement counterconditions the hope reaction (secondary reinforcement), resulting in a rapid loss of instrumental response strength. A more recent explanation of the PRE is offered by Lawrence and Festinger (1962). According to this theory, dissonance, which is a tensional state, is aroused on nonreinforced trials during acquisition. The organism is able to reduce dissonance through the attribution of added value to the stimulus conditions associated with nonreinforcement. In extinction, CRF-trained Ss experience dissonance for the first time and reduce this dissonance by not responding, however the "extra attractivensss" of the stimuli which have previously been associated with nonreinforcement serve to maintain responding for $\mathrm{PR}$-trained $\underline{\mathrm{S}}$, thus increasing resistance to extinction.

It is obvious that the PRE has generated not only a considerable amount of research but also continued efforts to devise theoretical formulations to account for the phenomenon.

Recently, experimental studies have appeared in the literature (e.g., Pavlik \& Reynolds, 1964: Pavlik \& Carlton, 1965; Spear E Pavlik, 1966) which suggest that the PRE is obtained only when a between-S experimental design is used. In a between- $\underline{S}$ design $\underline{S}$ is exposed to either PR or CRF, but not both, during acquisition, whereas in a within-S design $\underline{S}$ is exposed to both CRF and PR training conditions. The above studies indicate that when a within-s design is used,

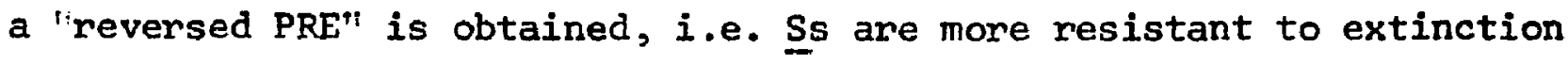


under conditions which have been previously associated with CRF . Some of these studies used a choice procedure, and it might be argued that such an apparatus is ill suited to the study of this phenomenon since it is by no means certain that a preference test and resistance to extinction measure the same function. Pavlik and Carlton (1965), however, used a free operant situation, wherein two different lights served as stimuli, one of which was associated with CRF during acquisition, and the other associated with PR. The "reversed PRE" was obtained within-Ss, and the authors suggest that the PRE, which is normally found when a between-S design is used, is simply a laboratory curiosity with little relevance to the exigencies with which an organism must cope in its natural environment. It is readily seen that such a statement has far-reaching implications for behavior theory and demands further investigation.

A number of studies which investigated the effect of effortfulness of response on resistance to extinction have shown that as effort required to make the instrumental response is increased, resistance to extinction decreases (e.g., Capehart, Viney $\varepsilon$ Hulicka, 1958; Mowrer E Jones, 1943: Solomon, 1948; Stanley E Aamodt, 1954). These studies used a within-S design, or at least subjected $\underline{S}$ to more than one level of effortfulness of response. Studies which have used a design wherein between-S comparisons are possible have shown that there is no difference in resistance to extinction as a function of effort (cf. Aiken, 1957: Applezweig, 1951: Maatsch, Adelman, E Denny, 1954). 
All of the above studies have used a CRF training procedure. Results of a more recent study (Young, 1966) showed a significant interaction between effortfulness of response and amount of PR training. Young used a between-ㅇ design and found that with approximately 1000 training trials resistance to extinction was a positive linear function of effort; whereas with twice as much training resistance to extinction was a negative linear function of effort. There were no differences in resistance to extinction as a function of effort or amount of training for CRF-trained $\underline{S}$. Thus, it appears that at least some of the variables affecting resistance to extinction interact in previously unsuspected ways.

The present study was designed to determine (1) whether the interaction obtained by Young (1966) will be obtained using a within$\underline{S}$ design, and (2) whether a "reversed PRE" or the usual PRE will be obtained when the stimuli associated with CRF and with PR are internal (as a function of effort). That both effects can be concomitantly studied is easily seen when it is considered that the PRE or "reversed PRE" comparisons will be made within levels of effort. 
METHOD

\section{Subjects}

The Ss were 96 naive male albino rats, 200-250 gm. in weight upon receipt at the latoratory.

\section{Apparatus}

The apparatus consisted of two identical operant chambers with plexiglass walls (10-1/4 in. deep; 13-1/2 in. long; 9 in. wide), each enclosed in a ventilated sound-insulated box. The floors were of hardware cloth and centered in the top of each box was a $1.12 \mathrm{w}$. Iight which was on at all times. A retractable metal bar ( 1 in. wide; $1 / 4$ in. thick), adjustable so as to require 11 or $44 \mathrm{gm}$. force to depress fully, was centered on the front wall 3 in. above the floor. The bar protruded into the box $5 / 8 \mathrm{in}$. The liquid dipper, which dispensed $.01 \mathrm{ml}$. of solution, was located 2 in. from the right edge of the bar, $1-1 / 2$ in. above the floor, and protruded into the box $3 / 8$ in. The dipper was accessible to $\underline{S}$ at all times except during actual operation of the dipper arm. All E-controlled events were operated by an electronic programming device and bar presses were automatically recorded on counters.

\section{Procedure}

Upon arrival at the laboratory, Ss were placed in individual cages and kept on an ad libitum food and water schedule for four days, 
after which Ss were placed on a food deprivation schedule consisting of $12 \mathrm{gm}$. Purina chow every $24 \mathrm{hr}$. Water was available in the cages at all times, and this food and water regimen was maintained throughout the experiment. The $\underline{S}$ were fed approximately $15 \mathrm{~min}$, after each experimental session.

From the 5 th to the 9 th day $S$ s were handled in pairs for 5 min. each day, and on the loth day Ss began magazine training on a VI-30 sec. schedule. Experimental periods consisted of 40 presentations of the dipper and were continued for four days. Reinforcement was a $40 \%$ liquid sucrose solution which was measured by percentage of weight and thus consisted of $40 \mathrm{gm}$. granulated sugar and $60 \mathrm{cc}$. water. The Ss were randomly assigned to training conditions which consisted of four within-S groups of 16 Ss each, and four between-S groups of 8 Ss each. Of the four within-S groups, Group I received 1000 total training trials, half of which were under conditions of CRF with a bar weighting of $11 \mathrm{gm}$. , and the other half under conditions of PR with a bar weighting of $44 \mathrm{gm}$. Group II received 1000 total training. trials, half of which were under conditions of CRF with a bar weighting of $44 \mathrm{gm}$, and the other half under conditions of PR with a bar weighting of $11 \mathrm{gm}$. Group III was identical to Group I, and Group IV was identical to Group II with the exception that Groups III and IV each received 2000 total training trials. AIl of the between-S groups experienced only one level of bar weighting throughout the experiment and all acquisition trials were under conditions of CRE. Group I received 1000 total training 
trials on the 44-gm. bar. Group II received 1000 total training trials on the 1I-gm. bar. Group III was identical to Group I, and Group IV was identical to Group II with the exception that Groups III and IV each received 2000 total training trials.

On the 14th day all Ss were conditioned to bar press. Those Ss which were to experience both levels of bar weighting during acquisition (within-s groups) were allowed to make 30 reinforced responses with the bar weighting set at $11 \mathrm{gm}$, and 30 reinforced responses with the bar weighting set at $44 \mathrm{gm}$. On the following day these Ss were allowed to make 50 reinforced responses with the bar weighting set at $1 \mathrm{gm}$, and 50 reinforced responses with the bar weighting set at $44 \mathrm{gm}$. Those Ss which were to experience only one level of bar weighting during acquisition (between-S proups) were allowed to make 60 reinforced responses with the appropriate bar weiphting on the day of conditioning, and on the following day these Ss were allowed to make 100 reinforced responses with the appropriate bar weighting.

On the 16th day Ss began acquisition trials which consisted of 100 bar presses daily. For the within-S groups, bar weighting, with its associated reinforcement schedule, was varied across experimental sessions in a random fashion, with the restriction that no more than two consecutive days were under identical training conditions. For the PR component of each schedule three different sequences of a VR-2 reinforcement schedule were used and were varied daily. A discrete trial procedure was used and the bar, which required 
$4 \mathrm{sec}$. to retract and extend fully, was inoperative during retraction. On the day following completion of acquisition trials extinction was started. Each within-S group was randomly divided with half of $S$ s in each group extinguished with a bar weighting of 11 gm., and the other half extinguished with a bar weighting of $44 \mathrm{gm}$. The group which received half of the acquisition trials under PR conditions with the heavy weight (44-gm.) bar (PRH), half of the acquisition trials under CRF conditions with the light weight (11-gm.) bar (CRL), and extinguished on the 44-gm. bar is identified as the PRHCRL-44 group. The other within-S groups are similarly identified and will be so referred to. During extinction the stimulus conditions were exactly the same as during acquisition with the exception that the dipper was inoperative. Extinction sessions were $15 \mathrm{~min}$. in length and continued for five days.

Design

The basic desifn of within- $\underline{S}$ groups was a $2 \times 2 \times 2$ factorial incorporating 11 or $44 \mathrm{gm}$. bar weightings; PRL-CRH or PRH-CRL training schedules, and 1000 or 2000 total trials. In addition, there was a 100\% reinforcement condition constituting a $2 \times 2$ factorial of between-S groups, incorporating 11 or $44 \mathrm{gm}$. bar weightings, and 1000 or 2000 total trials. The experiment was run in four replications with a replication consisting of two Ss from each cell in the experimental design. 


\section{RESULTS}

The total responses made by each $\underline{S}$ in extinction were recorded and the data for within-S groups were subjected to an analysis of variance, the results of which are summarized in Table 1. As shown therein, the main effects of Bar Weighting and Total Trials were significant beyond the .05 level: the Bar Weighting $x$ Total Trials $\times$ Schedule interaction was also significant beyond the .05 level, and these data were therefore subjected to an analysis of variance of simple interaction effects. Results of the analysis of variance of simple interaction effects (Table 2) indicate that the Bar Weighting $x$ Schedule interaction at 2000 Total Trials was significant beyond the .05 level, and these data were therefore subjected to an analysis of variance of simple effects, the results of which are summarized in Table 3 . As shown therein, at 2000 total trials, bar weighting for PRL-CRH was significant beyond the .05 level, and schedule at both $11-\mathrm{gm}$. and $44-\mathrm{gm}$. bar weightings was significant beyond the .05 level. These data are also presented in Fig. 1, where extinction responses are plotted against bar weighting by schedule. Examination of Fig. 1 shows that the PRL-CRH group was much more resistant to extinction on the $11-\mathrm{gm}$. bar than on the 44-gm. bar, whereas for the PRH-CRL group the difference was very slight, whether extinction occurred on the 1l-gm. or 44-gm. bar. 
TABLE 1

ANALYSIS OF VARIANCE OF RESPONSES IN EXTINCTION FOR WITHIN-S GROUPS

\begin{tabular}{|c|c|c|c|}
\hline Source & $d f$ & MS & $\mathbf{F}$ \\
\hline Bar Weighting (A) & 1 & $1,434.52$ & $12.77^{x}$ \\
\hline Total Trials (B) & 1 & $4,105.61$ & $10.77 *$ \\
\hline Schedule (c) & 1 & 1.76 & \\
\hline Replications (R) & 3 & 308.23 & 1.20 \\
\hline$A \times B$ & 1 & 446.26 & 3.36 \\
\hline$A \times C$ & 1 & 584.42 & 4.82 \\
\hline$B \times C$ & 1 & .17 & \\
\hline$A \times R$ & 3 & 112.36 & \\
\hline$B \times R$ & 3 & 381.29 & 1.49 \\
\hline$C \times R$ & 3 & 143.98 & \\
\hline$A \times B \times C$ & 1 & 819.41 & $11.21 *$ \\
\hline$A \times B \times R$ & 3 & 132.85 & \\
\hline$A \times C \times R$ & 3 & 121.35 & \\
\hline$B \times C \times R$ & 3 & 185.69 & \\
\hline$A \times B \times C \times R$ & 3 & 73.10 & \\
\hline Within & 32 & 256.69 & \\
\hline Total & 63 & & \\
\hline
\end{tabular}


TABLE 2

ANALYSIS OF VARIANCE OF SIMPLE INTERACTICN EFFECTS

FOR WITHIN-S GROUPS

\begin{tabular}{|c|c|c|c|}
\hline Source & df & MS & F \\
\hline $\begin{array}{l}\text { Bar weighting } \times \text { Total trials } \\
\text { for PRL-CRH }\end{array}$ & 1 & 1237.54 & 4.44 \\
\hline $\begin{array}{l}\text { Bar weighting } \times \text { Total trials } \\
\text { for PRH-CRL }\end{array}$ & 1 & 28.13 & \\
\hline $\begin{array}{l}\text { Bar weighting } \times \text { Schedule } \\
\text { for } 1000 \text { Total trials }\end{array}$ & 1 & 9.91 & \\
\hline $\begin{array}{l}\text { Bar weighting } \times \text { Schedule } \\
\text { for } 2000 \text { Total trials }\end{array}$ & 1 & 1393.90 & $10.53 *$ \\
\hline $\begin{array}{l}\text { Total trials } \times \text { Schedule } \\
\text { for } 11 \mathrm{gm} . \text { bar }\end{array}$ & 1 & 377.62 & \\
\hline $\begin{array}{l}\text { Total trials } \times \text { Schedule } \\
\text { for } 44 \mathrm{gm} . \text { bar }\end{array}$ & 1 & 421.96 & \\
\hline $\begin{array}{l}\text { Bar weighting } \times \text { Total trials } \times \\
\text { Replication for PRL-CRH }\end{array}$ & 3 & 278.97 & \\
\hline $\begin{array}{l}\text { Bar weighting } \times \text { Total trials } \times \\
\text { Replication for PRH-CRL }\end{array}$ & 3 & 160.77 & \\
\hline $\begin{array}{l}\text { Bar weighting } \times \text { Schedule } \times \\
\text { Replication for } 1000 \text { Trials }\end{array}$ & 3 & 173.81 & \\
\hline $\begin{array}{l}\text { Bar weighting } \times \text { Schedule } x \\
\text { Replication for } 2000 \text { Trials }\end{array}$ & 3 & 132.43 & \\
\hline $\begin{array}{l}\text { Total trials } \times \text { Schedule } x \\
\text { Replication for } 11 \text { gm. bar }\end{array}$ & 3 & 473.99 & \\
\hline $\begin{array}{l}\text { Total trials } \times \text { Schedule } \times \\
\text { Replication for } 44 \mathrm{gm} \text {. bar }\end{array}$ & 3 & 263.36 & \\
\hline
\end{tabular}




\section{TABLE 3}

ANALYSIS OF VARIANCE OF SIMPLE EFFECTS OF BAR WEIGHTING

AND SCHEDULE AT 2000 TOTAL TRIALS

\begin{tabular}{|c|c|c|c|}
\hline Source & $d f$ & MS & $\mathbf{F}$ \\
\hline Bar weighting for PRL-CRH & 1 & $3,124.81$ & $14.43 *$ \\
\hline Bar weighting for PRH-CRL & 1 & 9.61 & \\
\hline Schedule for $11 \mathrm{gm}$. bar & 1 & 720.93 & $32.31 *$ \\
\hline Schedule for $44 \mathrm{gm}$. bar & 1 & 673.41 & $33.62 \%$ \\
\hline $\begin{array}{l}\text { Bar weighting } \times \text { Replication } \\
\text { for PRL-CRH }\end{array}$ & 3 & 216.49 & \\
\hline $\begin{array}{l}\text { Bar weighting x Replication } \\
\text { for PRH-CRL }\end{array}$ & 3 & 49.27 & \\
\hline $\begin{array}{l}\text { Schedule x Replication for } \\
11 \mathrm{gm} \text {. bar }\end{array}$ & 3 & 22.31 & \\
\hline $\begin{array}{l}\text { Schedule x Replication for } \\
44 \mathrm{gm} \text {. bar }\end{array}$ & 3 & 20.03 & \\
\hline
\end{tabular}




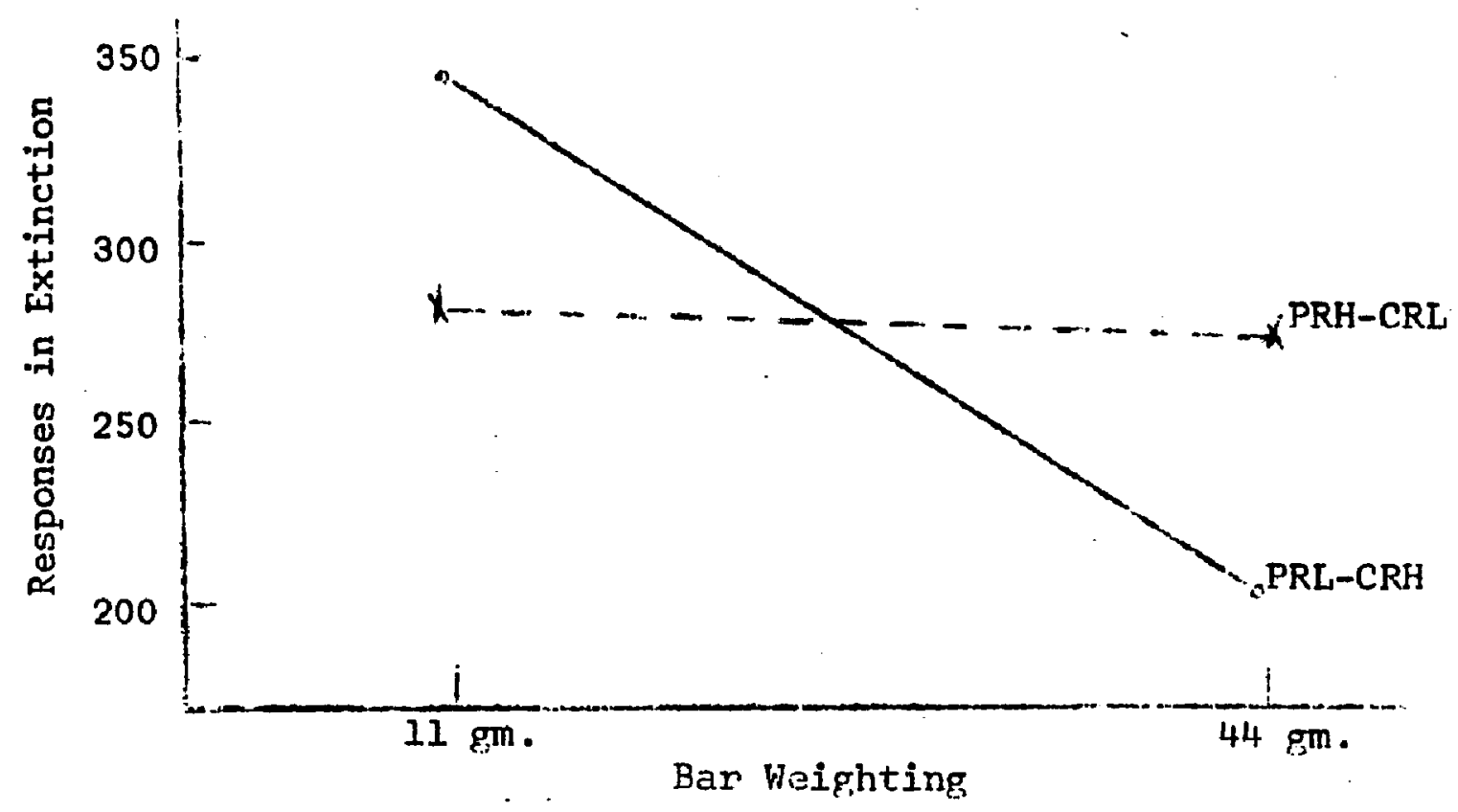

Fig. 1. Mean extinction responses for within- $\underline{S}$ groups at 2000 total trials. 
Firure 2 presents extinction responses plotted against total trials by bar weighting, and comparisons between these groups showed that at 1000 total trials the difference between 11-gm. and 44-gm. bar weighting was not significant, $t(30 \mathrm{df})=1.05$, whereas at 2000 total trials the difference between $11-\mathrm{gm}$. and 44-gm. bar weighting was significant beyond the .05 level, $t(30 \mathrm{df})=2.27$. Additional comparisons between groups showed that with 44-gm. bar weighting the difference between 1000 and 2000 total trials was significant beyond the .05 leve1, $t(30 \mathrm{df})=2.16$, whereas with 1.1-gm. bar weighting, the difference between 1000 and 2000 total trials was significant beyond the .05 level, $t(30 \mathrm{df})=3.69$. Examination of Fig. 2 indicates that resistance to extinction increased with increased training trials and, at 2000 trials, was greater when extinction occurred on the 11-gm. bar.

A further breakdown of the data is presented in Fig. 3 , where extinction responses are plotted apainst total trials by bar weighting and schedule. Examination of Fig. 3 indicates that within bar weighting at 1000 total trials, althouph the differences were not significant, slightly more responses were made when extinction occurred on the bar which had been associated with CRF during acquisition. Figure 3 also shows more clearly that within bar weighting at 2000 total trials: significantly more responses were made when extinction occurred on the bar which had been associated with PR during acquisition.

Figure 4 presents exiinction data of within-S groups extinguished on the bar weighting, which had been associated with PR during 


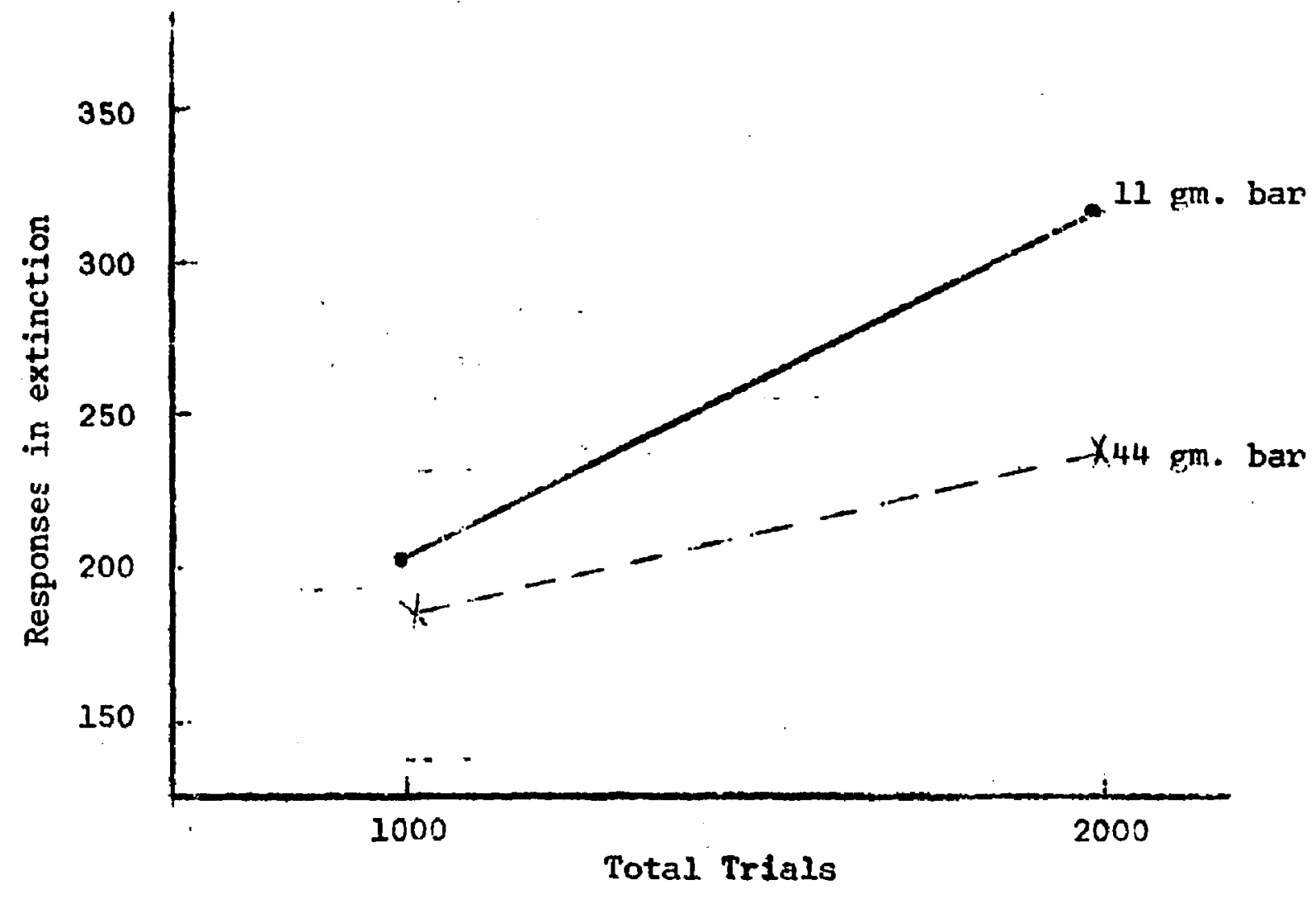

Fig. 2. Mean extinction responses for within- $\underline{S}$ groups by bar weighting. 


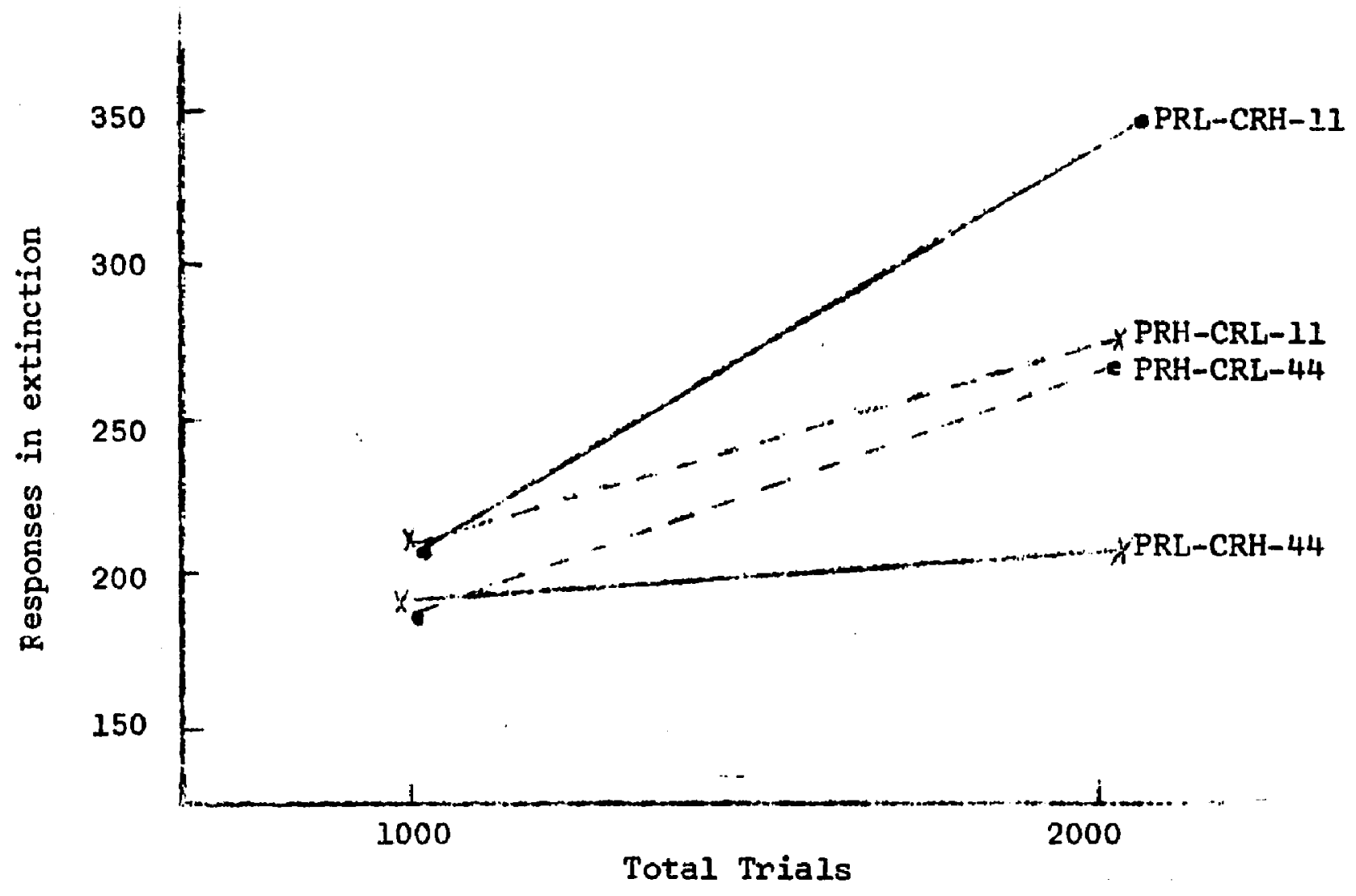

Fig. 3. Mean extinction responses for within-S groups by schedule and bar weighting. 


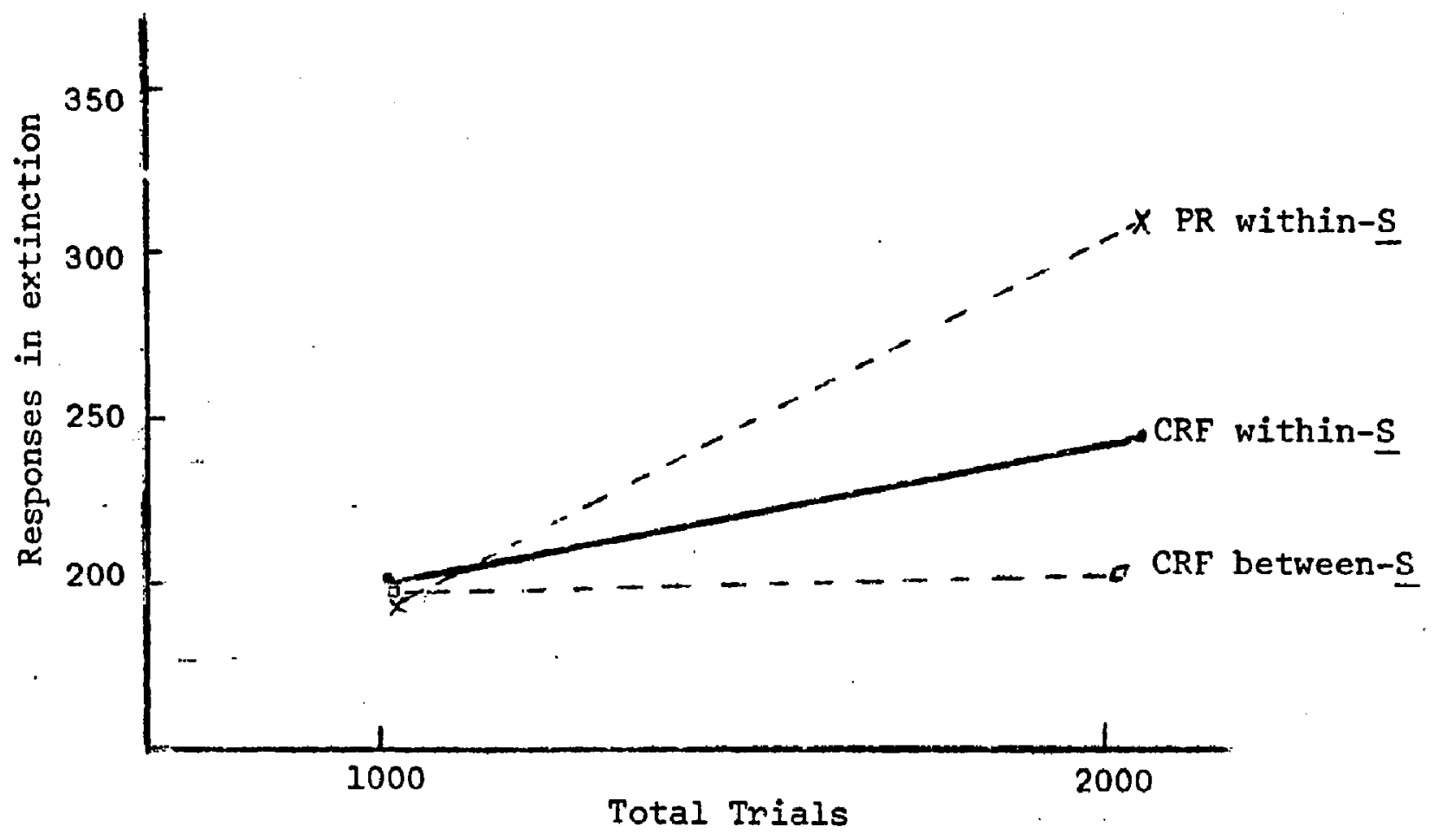

Fig. 4. A comparison of mean extinction responses for within- $\underline{S}$ and between- $\underline{S}$ groups by schedule. 
acquisition; within-S groups extinguished on the bar weighting which had been associated with IRF during acquisition: and betreen-S groups which experienced only CRF during acquisition. As shown in Fig. 4, at 1000 total trials extinction responses were almost identical for these three groups: however, at 2000 total trials the within-S PR group made significantly more extinction responses than the within-S CRF group, $t,(30 \mathrm{df})=2.00$. Although the within-S CRF group made more extinction responses than the between-S CRF group, this difference was not significant, $t,(30 \mathrm{df})=1.59$.

The data for between-S (CRF-trained) Ss were subjected to an analysis of variance, the results of which are summarized in Table 4. As shown therein, neither Bar Weighting, Total Trials, ncr the Bar Weighting $\times$ Total Trials interaction was significant. These data are also presented in Figure 5, where extinction responses are plotted against total trials by bar weighting. Examination of Fig. 5 shows that the differences between groups were very small, and the means were almost identical for all groups. 
TABLE 4

ANALYSIS OF VARIANCE OF EXTINCTION RESPONSES OF

BETWEEN-S (CRF-TRAINED) GROUPS

\begin{tabular}{lccc}
\hline Source & df & MS & $F$ \\
\hline Bar weighting (A) & 1 & 5.95 & \\
Total trials (B) & 1 & 9.03 & \\
Replications (C) & 3 & 54.63 & \\
A X B & 1 & 120.91 & 1.53 \\
A X C & 3 & 46.95 & \\
B X C & 3 & 55.70 & \\
A X B X C & 3 & 78.89 & \\
Within & 16 & 108.49 & \\
\hline Total & 31 & & \\
\hline
\end{tabular}




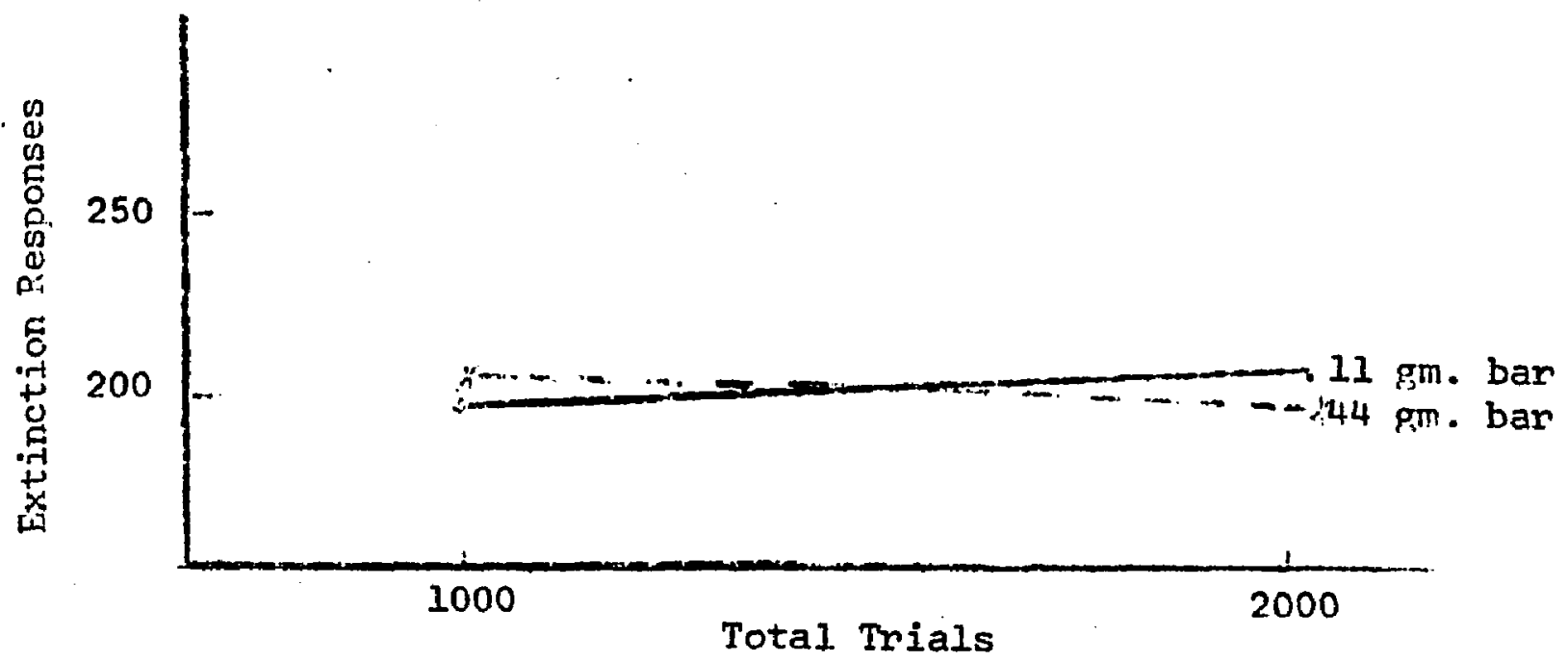

Fig. 5. Mean extinction responses for between-s (CRFtrained) groups by bar weighting. 


\section{DISCUSSION}

Although the interaction obtained by Young (1966) was not found in the present study, the different results probably should not be attributed solely to the difference between within-S and between-으 designs. Other factors, such as different ratios of nonreinforced to reinforced trials, as well as different trial procedures, could have contributed to the different results.

The present finding that for within- $\underline{S}$ groups resistance to extinction decreased as the effort required to make the instrumental response increased is in agreement with previous studies (e.g., Capehart, Viney, \& Hulicka, 1958). The present results also-show that for between-으 groups there was no difference in resistance to extinction as a function of effort, which likewise agrees with previous studies which have manipulated the effort variable (e.g., Applezweig, 1951).

The most critical finding in this study is that for within-S groups a clear, conventional PRE was obtained within levels of effort at 2000 training trials. An examination of Fig. 3 indicates that the PRE and the effect of differential bar weighting were of almost equal strength. That the PRE was not obtained at 1000 trials probably should be attributed to generalization when it is considered that, to produce the effect, it was necessary for response-produced proprioceptive stimuli, which probably differ only to a small degree, 
to become differentially associated with PR and with CRF. Although the differences between within-S groups at 1000 trials were small, more responses were made on the bar which had been associated with CRF during acquisition, and this suggests that with fewer training trials a 'reversed PRE' might have been obtained. Pavlik and Carlton (1965) obtained a reversed PRE using a bar press procedure: in that study, however, experimental sessions were time dependent and therefore provided no control over total trials or total nonreinforced trials. Their results, therefore, could have been due to fewer training trials, although previous studies (e.g., Lawrence $\varepsilon$ Festinger, 1962; (hl \& Young, 1967) have shown that the absolute number of nonreinforced trials during acquisition is a more significant factor in determining resistance to extinction.

Pavlik, Carlton, and Manto (1965) controlled both total responses and total number of reinforcements and obtained a conventional PRE within-Ss. They interpretated their results on the basis of chained behavior established as a function of the experimental procedure used. Their interpretation probably is correct in view of the fact that the present study indicates that the PRE. is response specific, which is to say that whatever causes the effect of PR becomes attached in some way to the stimuli produced by the instrumental response. Similar results were obtained by Theios and Polson (1962) and by Trapold and Doren (1966). In the Trapold and Doren study reinforced and nonreinforced direct placements in the goal box were interspersed between CRF training trials 
in a runway. Their results showed that nonreinforced direct placement trials produced the PRE in extinction only if $\underline{S}$ was required to run, in the goal box, to the food cup. The Ss which had direct placements at the food cup in the goal box, thus eliminating the locomotor response, showed no PRE in extinction.

The suggestion that the PRE is response specific is further . supported by the results of an experiment reported by Amsel (1967). In that study rats were run to $P R$ in a black (or white) alley and to CRF in a white (or black) alley. Both between-s and within-s comparisons were possible. Extinction results showed a clear PRE for the between-S groups; however, a generalized PRE (Brown $\varepsilon$ Logan, 1965). was obtained for within-S groups. Amsel suggested that the absence of the usual PRE for within- $\underline{S}$ groups was due to generalization of the PRE from the stimulus alley previously associated with PR to the stimulus alley previously associated with CRF. It is here suggested, however, that since the same (running) response was made to both stimuli, and since the PRE was attached to the response-produced stimuli, then no differences should be expected in extinction for within-s groups. In the present study a comparison of extinction responses for CRF within-S groups and CRF between-S groups at 2000 trials (Fig. 4) indicates that there was a certain amount of generalization of the PRE from the stimuli previously associated with PR. This should not, however, detract from the idea that the PRE is specific to the response-produced stimuli. when it is considered that essentialiy the same response and probably very similar response- 
produced stimuli have been differentially reinforced.

Further evidence which supports the idea that the PRE is response specific is provided by the results of a study by Rashotte (1966). Rashotte differentially reinforced within-S groups for running in a very narrow, white alley, and for running and climbing in a wide, black alley. A within-S PRE was obtained which indicates that the PRE was attached to the response-produced stimuli of running, or of running and climbing, but not both. Rashotte's hypothesis, within the framework of conditioned frustration theory (Amsel, 1958, 1962), was that during within-s acquisition the fractional anticipatory frustration-produced stimuli $\left(s_{f}\right)$ become conditioned to the specific response made to the stimulus associated with PR (SI), and that this response is subsequently evoked by $s_{f}$ during extinction to both $S 1$ and to the stimulus previously associated with CRF (S2). Thus, if the response evoked by $s_{f}$ does not compete with the response made to 52 , then responding to 52 should be maintained. This interpretation would not be applicable to the results of the present study, however, because the stimuli which were associated with either $P R$ or CRF were not present until the instrumental response was made.

If the PRE is response specific, as indicated by the present results and by the evidence just considered, this would indicate that most of the theoretical formulations of the PRE, which were considered earlier, are inadequate. Although Trapold and Doren (1966) relied upon conditioned frustration theory to account for 
their results, it is suggested that the manner in which they did so is improper. Conceivably, these results could be made to fit within the framework of conditioned frustration theory, but this would seem to require rather tortuous reasoning.

It could be angued that Logan's hypothesis (Logan, Beier, $\varepsilon$ Kincaid, 1956; Logan, 1960) might account for the present results. According to Logan, the extinction of an instrumental response is due, at least in part, to the loss of incentive motivation, which is dependent upon the fractional anticipatory goal response $\left(r_{g}\right)$. Resistance to extinction is thus increased by any training procedure which permits extinction of $r_{g}$ to the cues which occur on nonreinforced trials after the regular time of reinforcement. Is stated, the theory would not predict the present results, although it might be suggested that $r_{g}$ is present only until the occurrence of the response-produced stimuli which are followed by intermittant nonreinforcement. This requires a modification of the theory, however.

The only theoretical formulation which specifically considers the stimuli produced by the instrumental response is that of Mowrer (1960). This theory would suggest that during training on the bar weight associated with $\mathrm{CRF}$ the response-produced stimuli have only hope" (secondary reinforcement) conditioned to them; whereas on the bar weight associated with $P R$ the response-produced stimuli have been followed by both the goal response and the frustrative reaction which occurs on nonreinforced trials. Since the "image" (conditioned sensation) of the frustrative reaction, which occurs 
as the response is made, is occasionally followed by reinforcement, on future nonreinforced trials the 'hope reaction"' (secondary reinforcement) generalizes from the conditioned sensation to physical reality. Thus, the present results would appear to be as Mowrer's theorizing would predict. Hhat is not clear, however, is why Mowrer feels that it is necessary to rely on differences in discriminative capacities on the part of $P R$ - and CRF-trained Ss to account for the differences in resistance to extinction. If, as Mowrer supgests, the frustrative reaction, which occurs on nonreinforced trials, becomes counterconditioned by secondary reinforcement during PR training, this in itself should account for the differences in resistance to extinction between $P R-$ and CRF-trained Ss. To add to this that the after-response "image" of PR-trained Ss is ambiguous seems unnecessary. 
SUMMARY

Ninety-six male albino rats were conditioned to bar press in a modified skinner box for a $40 \%$ sucrose solution. The basic design of within-S groups was a $2 \times 2 \times 2$ factorial incorporating 11 or 44 gm. bar weightings, PRL-CRH or PRH-CRL training schedules, and 1000 or 2000 total training trials. In addition, there was a $100 \%$ reinforcement condition constituting a $2 \times 2$ factorial of between-S groups incorporating 11 or $44 \mathrm{gm}$. bar weightings, and 1000 or 2000 total training trials. The experiment was run in four replications with a replication consisting of two Ss from each cell in the experimental design. Results showed that for within-S groups there were no differences in resistance to extinction at 1000 trials: at 2000 trials, however, a clear, conventional PRE was obtained within levels of effort. Results further indicated that for within-s groups resistance to extinction increased with increased training trials, and decreased as a function of effort. There were no differences in resistance to extinction for between-S groups, either as a function of bar weighting or as a function of total training trials. Results were interpreted in terms of Mowrer's theoretical formulation of the PRE. 


\section{BIBLIOGRAPHY}

Aiken, E. G. The effort variable in the acquisition, extinction, and spontaneous recovery of an instrumental response. J. exp. Psychol., 1957, 53, 47-51.

Amsel, A. The role of frustrative nonreward in noncontinuous reward situations. Psychol. Bull., 1958, 55, 102-119.

Amse1, A. Frustrative nonreward in partial reinforcement and discrimination learning: Some recent history and a theoretical extension. Psychol. Rev., 1962, 69, 306-328.

Amsel, A, Partial reinforcement effects on vigor and persistence: Advances in frustration theory derived from a variety of within-subjects experiments. In Spence, K. H., Spence, J. T., and Anderson, N. (eds.) The Psychology of learning and motivation: Advances in research and theory. New York: Academic Press (in press).

Applezweig, M. H. Response potential as a function of effort. J. comp. physiol. Psychol., 1951, 44, 225-235.

Bitterman, M. E., Feddersen, W. E., and Tyler, D. W. Secondary reinforcement and the discrimination hypothesis. Amer. J. Psychol. , 1953, 66, 456-464.

Brown, R. T., and Logan, F. A. Generalized partial reinforcement effect. J. comp. physiol. Psychol., 1965, 60, 64-69.

Capaldi, E. J. The effect of different amounts of training on the resistance to extinction of different patterns of partially reinforced responses. J. comp. physiol. Psychol., 1958, 51, 367-371.

Capehart, J., Viney, W., and Hulicka, I. M. The effect of effort upon extinction. J. comp. physiol. Psychol., 1958, 51 . 505-507.

Denny, M. R. The role of secondary reinforcement in a partial reinforcement learning situation. J. exp. Psychol., 1964, 36, 373-389. 
Elam, C. B., Tyler, D. W., and Bitterman, M. E. A further study of secondary reinforcement and the discrimination hypothesis. J. comp. physiol. Psychol., 1954, 47, 381-384.

Freides, D. Goal-box cues and pattern of reinforcement. J. exp. Psychol., 1957, 53, 361-371.

Hulse, S. H. Jr., and Stanley, W. C. Extinction by omission of food as related to partial and secondary reinforcement. J. exp. Psychol., 1956, 52, 221-227.

Humphreys, L. G. The effect of random alternation of reinforcement on the acquisition and extinction of conditioned eyelid reactions. J. exp. Psychol., 1939, 25, 141-158.

Jenkins, W. O., and Stanley, J. C. Jr. Partial reinforcement: A review and critique. Psychol. Bull, 1950, 47, 193-234.

Katz, s. Stimulus aftereffects and the partial reinforcement extinction effect. J. exp. Psychol., 1957, 53, 167-172.

Kendler, H., Pliskoff, S., D'Amato, M., and Katz, S. Nonreinforcements vs. reinforcements as variables in the partial reinforcement effect. J. exp. Psychol., 1957, 53, 269-276.

Lawrence, D. H., and Festinger, L. Deterrents and reinforcements: The psychology of insufficient reward. Stanford: Stanford Univer. Press, 1962 .

Lewis, D. J. Acquisition, extinction, and spontaneous recovery as a function of percentage of reinforcement and intertrial intervals. J. exp. Psychol., 1956, 51, 45-53.

Lewis, D. J. Partial reinforcement: A selective review of the literature since 1950. Psychol. Bull., 1960, 57, 1-28.

Logan, F. A., Beier, E. M., and Kincaid, W. D. Extinction following partial and varied reinforcement. J. exp. Psychol., $1956, \underline{52}, 65-70$.

Logan, F. A. Incentive. New Haven: Yale Univer. Press, 1960.

Maatsch, J. L., Adelman, H. M., and Denny, M. R. Effort and resistance to extinction of the bar-pressing response. J. comp. physiol. Psychol., 1954, 47, 47-50.

Mason, D. J. The relation of secondary reinforcement to partial reinforcement. J. comp. physiol. Psychol., 1957, 50, 264-268. 
Mowrer, O. H. Learning theory and behavior. New York: Niley, 1960.

Mowrer, 0.H. Learning theory and the symbolic processes. Wiley,

Mowrer, O. H., and Jones, H. M. Extinction and behavior variability as functions of effortfulness of task. J. exp. Psychol., $1943,33,369-386$.

Mowrer, O. H., and Jones, H. H. Habit strength as a function of the pattern of reinforcement. J. exp. Psychol., 1945, 35, 293311.

Notterman, J. M: A study of some relations among aperiodic reinforcement, discrimination training, and secondary reinforcement. J. exp. Psychol., 1951, 41, 161-169.

Pavlik, W. B., and Carlton, P. L. A reversed partial-reinforcement effect. J. exp. Psychol., 1965, 70, 417-423.

Pavlik, W. B., Carlton, P. L., and Manto, P. G. A further study of the partial reinforcement effect within-subjects. Psychon. Sci. , 1965, 3, 533-534.

Pavlik, W. B., and Reynolds, W. F. Conventional and reversed partial reinforcement effects in selective learning. Psychon. Sci., $1964,1,155-156$.

Rashotte, M. E. Frustrative factors in persistence: within- and between-S comparisons. Unpublished doctoral dissertation, Univer. of Toronto, 1966.

Sheffield, Virginia F. Extinction as a function of partial reinforcement and distribution of practice. I. exp. Psychol., $1949,39,511-526$.

Skinner, B. F. The behavion of organisms: an experimental analysis. New York: Appleton-Century, 1938.

Solomon, R. L. Effort and extinction rate: A confirmation. I. comp. physiol. Psychol., 1948, 41, 93-101.

Spear, H. E., and Pavlik, W. B. Percentage of reinforcement and reward magnitude effects in a $T$ maze: between and within subjects. J. exp. Psychol., 1966, 71, 521-528.

Spence, K. W. Behavior theory and learning. Englewood Cliffs, N. J.: Prentice-Hall, 1960 . 
Stanley, W. C., and Aamodt, H. S. Force of responding during extinction as a function of force requirement during conditioning. J. comp. physiol. Psychol., 1954, $47,462-464$.

Theios, J., and Polson, P. Instrumental and goal responses in nonresponse partial reinforcement. J. comp. physiol. Psychol., $1962,55,987-991$.

Trapold, M. A., and Doren, D. G. Effect of noncontingent partial reinforcement on the resistance to extinction of a runway response. J. exp. Psychol., 1966, 71, 429-431.

Tyler, D. W. Extinction following partial reinforcement with control of stimulusmgeneralization and secondary reinforcement. Amer. J. Psychol., 1956, 69, 359-368.

Tyler, D. W., Wortz, E. C., and Bitterman, M. E. The effect of random and alternating partial reinforcement on resistance to extinction in the rat. Amer. J. Psychol., 1953, 66, 57-65.

Uhl, C. N., and Young, A. G. Resistance to extinction as a function of incentive, percentage of reinforcement, and number of nonreinforced trials. I. exp. Psychol., (in press).

Weinstock, S. Resistance to extinction of a running response following partial reinforcement under widely spaced trials. J. comp. physiol. Psychol., 1954, 47, 318-322.

Weinstock, S. Acquisition and extinction of partially reinforced running, response at a 24-hr. intertrial interval. J. exp. Psychol., 1958, 56, 151-158.

Wilson, W., Weiss, E. J., and Amsel, A. Two tests of the Sheffield hypothesis concerning resistance to extinction, partial reinforcement and distribution of practice. J. exp. Psychol., $1955,50,51-60$.

Young, A. G. Resistance to extinction as a function of number of nonreinforced trials and effortfulness of response. J. exp. Psychol., 1966, 22, 610-613. 